\title{
Apoptosis, cell proliferation and serotonin immunoreactivity in gut of Liza aurata from natural heavy metal polluted environments: preliminary observations
}

\author{
S. Ferrando, ${ }^{a, b}$ T. Ferrando, ${ }^{b}$ L. Girosi, ${ }^{b}$ A. Mauceri, ${ }^{a}$ S. Fasulo, ${ }^{a}$ G. Tagliafierro ${ }^{b}$ \\ aDipartimento di Biologia Animale ed Ecologia Marina, Università di Messina; 'Dipartimento di Biologia, \\ Università di Genova, Italy
}

(C2005, European Journal of Histochemistry

In the present paper, the effect of natural environment nonlethal heavy metal concentration on cell renewal of Liza aurata intestinal epithelium, was studied by the TUNEL (terminal deoxynucleotidyltransferase-mediated dUTP nick end labelling) method and anti-PCNA (proliferating cell nuclear antigen) immunohistochemistry, in order to detect, respectively, apoptosis and cell proliferation. In addition, the presence and distribution of the cell renewal regulator, serotonin, was immunohistochemically investigated. In order to reduce variability, only immature specimens were considered. The results indicated that in the control specimens from non-polluted areas, the PCNA immunoreactive nuclei of the proximal intestinal epithelium were only located at the bottom of the intestinal folds, together with a few TUNEL-positive nuclei, and goblet mucous differentiated cells. In the specimens from polluted areas, the number of PCNA immunoreactive cells was greatly enhanced, and they extended along the mid portion of the intestinal folds; the number of TUNEL-positive nuclei was enhanced as well, but they were almost exclusively detected in the third apical portion of the intestinal folds. Serotonin immunoreactive nerve elements were more frequently detected in the intestinal wall of $L$. aurata specimens from polluted areas, and besides that, some serotonin immunoreactive endocrine cells were also present. Variations in distribution and frequency of TUNEL-positive nuclei, PCNA immunoreactive nuclei, and serotonin immunoreactivity put in evidence an alteration of cell renewal with an enhancement of cell proliferation, probably leading to morphological intestinal fold changes.

Key words: mullet, gut, apoptosis, cell proliferation, serotonin, heavy metals.

Correspondence: Sara Ferrando,

Dipartimento di Biologia, Università di Genova

Viale Benedetto XV, 5, 16132 Genova, Italy

Tel: +39.010.3537015.

Fax: +39.010 .3538047$

E-mail: sara.ferrando@unige.it

Paper accepted on September 23, 2005

European Journal of Histochemistry

2005; vol. 49 issue 4 (Oct-Dec): 331-340
I $\mathrm{t}$ is well known that environmental heavy metal pollution causes numerous alterations in water organisms (Wendelaar Bonga and Lock, 1992; Dang et al., 1999; de la Torre et al., 2000; Fossi et al., 2002; de Oliveira Ribeiro et al., 2002; Kilemade et al., 2002; Stentiford et al., 2003). In particular, heavy metals represent a risk because they persist in the environment and accumulate in biological tissues. The assessment of their effects is difficult because there are numerous interactions between metals and endogenous substances. In the end, these interactions have consequences not only on the organisms but also on the whole ecosystem. So it is very important, in order to assess the environment risk for these pollutants, to take into account not only physical and chemical parameters but also biochemical, physiological and histo-cytopathological parameters.

Fish are often considered as a useful tool for this kind of research because they can be considered as the end point of the trophic chain in their environment (van der Oost et al., 2003); in particular, the use of cytological biomarkers for monitoring the marine coastal environment has been recommended $(\mathrm{Au}, 2004)$. Cell death and proliferation have been also proposed as biomarkers (Ortego et al., 1995; Piechotta et al., 1997) and their distribution patterns seem to be related to environmental heavy metal toxicity (Waalkes et al., 2000). Alterations of epithelial renewal were observed in various fish organs such as branchial epithelium (Ferrando et al., 2005a; Mauceri et al., 2005), skin (Kilemade et al., 2002), gonads (Lyons et al., 2004) and liver (Piechotta et al., 1997; Feng et al., 2003; Risso-de Faverney et al., 2004). In mammals, it has been demonstrated that the intestinal epithelium, normally renewed by regular processes of proliferation and apoptosis (Stroband and Debets, 1978), can be affected by radiation, disease or exposure to toxi- 
cants (Radecki et al., 1992; Potten \& Booth, 1997; Waalkes et al., 2000); in fish, intestinal epithelial cell renewal seems to be affected by $\mathrm{Cu}$ - and $\mathrm{Cd}$ experimentally contaminated food (Lundebye et al., 1999; Berntssen et al., 2001).

In this study, we wanted to assess the effects of environmental heavy metal pollution on the renewal of the fish intestinal epithelium and to relate this aspect with the presence and distribution of serotonin immunoreactivity (ir). From literature, it is known that serotonin (5-hydroxytryptammine, 5HT) modulates cell renewal in different tissues, and in particular, proliferation, migration and maturation in a variety of cell types (Azmitia, 2001). Furthermore, it is known that the exposure to heavy metals can affect the presence of 5-HT ir in the tissue of different invertebrates (Salánki and Hiripi, 1990; Almeida et al., 2003), and vertebrates (Antonio et al., 2002; Lafuente et al., 2003), including fish (Franchini et al., 1999; Rademacher et al., 2003). Cell proliferation was detected through proliferating cell nuclear antigen (PCNA) immunolabelling and apoptosis through the TUNEL method. PCNA is a highly conserved molecule, essential for the synthesis of DNA in the S-phase of the cell cycle; PCNA immunodetection is commonly used as a marker of cell proliferation, although this antigen can be found in the cells along the G1G2 phase, albeit at low concentration (Suzuki et al., 1992). The TUNEL method is generally indicative of cell apoptosis, but it can be more properly related to the late phase of this process; early apoptotic cells are TUNEL negative as are necrotic cells.

The species $L$. aurata is particularly suitable for this study for its feeding habits (benthic organisms and detritus) (Ben-Tuvia et al., 1986) favouring bio-accumulation. Specimens were sampled from the brackish waters of Lake Faro and Lake Ganzirri (Capo Peloro, Messina, Italy), where the presence of heavy metals was previously characterized (Giacobbe et al., 1996; Munaò et al., 2000; Mauceri et al., 2002). These two lakes show different concentrations of heavy metals; in particular, in Lake Faro, $\mathrm{Pb}$ levels five time higher than those in Lake Ganzirri have been detected (Munaò et al., 2000). The levels of Pb, Cd and $\mathrm{Hg}$ in the gills and kidney of $L$. aurata collected from these two lakes were also determined, and a level of $\mathrm{Pb}$, higher than that detected in non-polluted fish, was found (Mauceri et al., 2005). Furthermore, more important histopathological gut modifications were observed in fish from Lake Ganzirri (Ferrando et al. 2005b).

As a reference site, the protected area of Lake Verde in Marinello Lagoons (Regione Sicilia, Assessorato Territorio e Ambiente, 2002) was chosen. In order to diminish the variability due to sex gender or to a particular phase of the reproductive cycle, only immature specimens were considered. The widespread distribution of $L$. aurata and its resistance to different environmental conditions make it a good candidate as a biomarker model, especially for chronic toxicant exposure. The impairment of cell renewal observed in our specimens from polluted areas could be the principal cause of the morphological alterations of the gut mucosa previously observed in L. aurata from the same environment (Ferrando et al., 2005a).

\section{Materials and Methods}

A total of forty four immature specimens (length $18-20 \mathrm{~cm}$ ) of the golden grey mullet $L$. aurata (Order: Perciformes; Family: Mugilidae), 9 from Lake Verde, 15 from Lake Faro and 20 from Lake Ganzirri (Messina, Italy), were collected during the spring and autumn of 2001, 2002 and 2003.

Lake Faro and Lake Ganzirri (Capo Peloro, Messina, Italy) were previously studied for their chemical content, and they are considered as high polluted environments, in particular for the presence of elevated concentrations of heavy metals (Giacobbe et al.,1996; Munaò et al., 2000; Mauceri et al., 2002). Brackish Lake Faro is characterized by the presence of hydrogen sulphide, many photosynthetic sulphur microrganisms and the following concentrations of metals: Al 36.56 $\mu \mathrm{g} / \mathrm{L} ; \mathrm{Fe} 20.7 \mu \mathrm{g} / \mathrm{L} ; \mathrm{Cd} 48.4 \mu \mathrm{g} / \mathrm{L} ; \mathrm{Pb} 5.2 \mu \mathrm{g} / \mathrm{L}$, $\mathrm{Hg} 55.5 \mu \mathrm{g} / \mathrm{L}$; during summer, the water temperature at the interface can rise to $29^{\circ} \mathrm{C}$ while at a depth of $20 \mathrm{~m}$ the water temperature is $19^{\circ} \mathrm{C}$.

Brackish Lake Ganzirri is only 7 meters deep, characterized by the following concentrations of heavy metals: Al $21.6 \mu \mathrm{g} / \mathrm{L} ; \mathrm{Fe} 74.7 \mu \mathrm{g} / \mathrm{L} ; \mathrm{Cd} 68.4$ $\mu \mathrm{g} / \mathrm{L}, \mathrm{Pb} 1.2 \mu \mathrm{g} / \mathrm{L} ; \mathrm{Hg} 32.5 \mu \mathrm{g} / \mathrm{L}$; during summer the water temperature can rise to $29.8^{\circ} \mathrm{C}$ (Munaò et al., 2000).

Lake Verde (Marinello) is routinely monitored as a protect area of the Regione Sicilia (Regione Sicilia, Assessorato Territorio e Ambiente, 2002) and it has been considered as reference site. Fish were anesthetized with $0.01 \%$ MS Sandoz 222 
(tricainemethanesulfonate; Argent, Redmond, WA, USA; dilution 1:1000) before being killed and dissected to collect gut samples. They were fixed in $4 \%$ paraformaldehyde in $0.1 \mathrm{M}$ phosphate buffered solution ( $\mathrm{pH}$ 7.4) at $4^{\circ} \mathrm{C}$ and Paraplast (BioOptica, Italy) embedded.

The proximal portion of the intestine near the openings of the pyloric ceca was transversally sectioned and $1 / 4$ of the whole mucosal circumference (about 10 folds) was used as a length unit for our observations.

Groups of four serial sections ( $5 \mu \mathrm{m}$ thick) were either stained for histological observations by Haematoxylin-Eosin (Bioptica, Italy), treated for apoptosis and proliferation detection, or for serotonin immunostaining. Apoptosis was assessed on the evidence of morphological characteristics, such as cell shrinkage, chromatin condensation with DAPI staining, as well as by a fluorescein-conjugated TUNEL method (terminal deoxynucleotidyltransferase-mediated dUTP nick end labelling, Roche, F). Proliferation was immunodetected by a rabbit anti-proliferating cell nuclear antigen (PCNA) polyclonal antiserum (1:200 in PBS, Santacruz Biotechnology, USA). PCNA is a nuclear antigen whose expression increases during $S$ phase. For proliferative cell counting, only the strongly immunostained nuclei were considered. Serotonin ir was assessed using a rabbit polyclonal serotonin antiserum (prediluted, Biomeda, USA). As secondary antisera, either FITC-conjugated (1:400 in PBS, DAK0, DK), Alexafluor 488 or Alexafluor 594-conjugated anti-rabbit ( $1: 800$ in PBS, Molecular Probes, NL) antisera were used. For fluorescence observations, nuclear DAPI counterstaining (1:1000, Molecular Probes, NL) was carried out.

Sections were examined under a BX60 Olympus microscope (light and epi-fluorescence microscope), visualized through the Color-View Camera (Olympus, Japan). The images were acquired and analysed through the software AnalySIS (Soft Imaging System, USA). TUNEL method and PCNA immunodetection were also performed on the same section using the red Alexafluor 594-conjugated anti-rabbit antiserum. The overlapping of TUNEL and PCNA positivity were obtained using Adobe Photoshop CS software. The specificity of the immunoreaction was controlled by substitution of the primary antiserum with PBS or replacement of the primary antiserum with non-immune rabbit serum diluted 1:200.

In order to score the number of the different positive cells and their distribution along the folds, 1/4 of the whole surface of the gut transversal sections (28-30 mm epithelium surface) was considered. All measurements and the counting of the various cell types were done using the ImageJ software (Rasband, 2005) and repeated for three transverse sections of the analysed specimens. All data are expressed as means \pm SD.

\section{Results}

Histomorphology - The histomorphological appearance of the $L$. aurata intestinal wall was previously described (Ferrando et al., 2005b). The morphology of the intestinal folds varied according to the lake they came from and to its degree of pollution: in the control specimens, folds appeared as fingershaped villi (Figure 1a), but in the specimens from the polluted lakes, most of the folds looked like long extended lamellar ridges, with a flattened apex. The intestinal folds were lined by a columnar absorptive epithelium characterized by intercalating mucous goblet cells. No morphologically-distinct proliferative units were detected. The bottom of the folds in the immature specimens was constituted by nondifferentiated cells with a few mucous goblet cells. In samples from the Faro and Ganzirri Lakes, the intestinal wall showed dilated blood vessels and numerous eosin-stained granulocytes in the lamina propria. The most numerous goblets cells were observed in Lake Faro samples. Mitosis was rarely detected.

Apoptosis detection - In the control fish intestinal epithelium, very few TUNEL-positive elements were detected; it was estimated that about one apoptotic cell is seen in every fifth histological longitudinal crypt section (equivalent to less than $1 \%$ of the crypt cell number); they were almost exclusively located at the bottom of the folds (Figure 1b). In the Lake Ganzirri specimens, TUNEL-positive nuclei were instead present at the apex (Figure 1c), or along the side of the third apical portion of the intestinal folds; this distribution and the frequency of the TUNEL-positive nuclei can be better observed in the fold transverse sections (Figure 1d). More numerous TUNEL-positive nuclei were detected in the intestinal mucosa from Lake Faro specimens; most of them were located at the apical third of the villi (Figure 1e), but they were also 

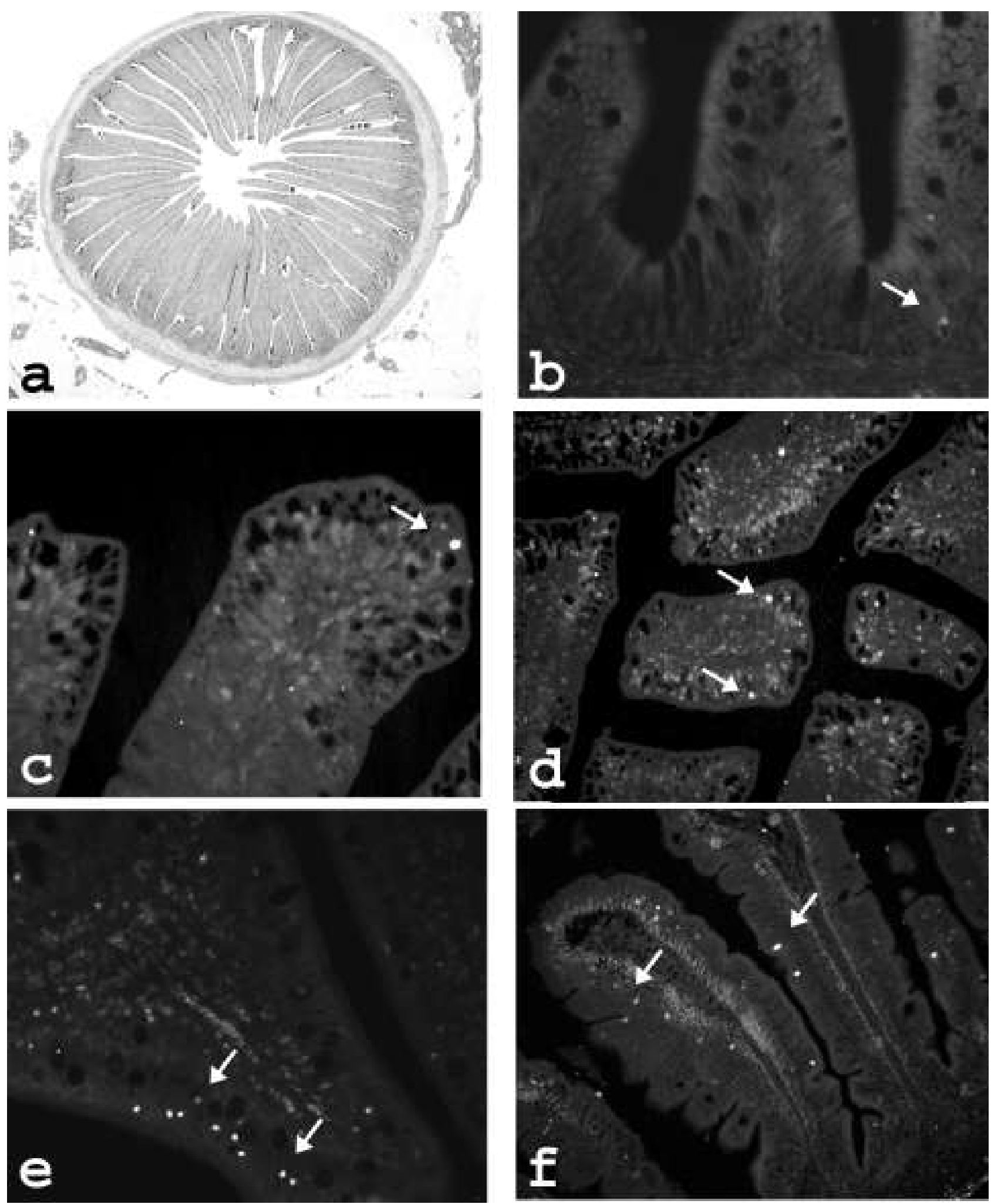

Figure 1. a) Gut transversal section of $L$. aurata from Verde Lake, showing finger like villi. Alcian PAS - X15. b - f) Gut transversal section of $L$. aurata, TUNEL method. Arrows = apoptotic nuclei. b) Specimen from Verde Lake with very few apoptotic nuclei at the fold base - X200. c) Specimen from Ganzirri Lake, two apoptotic nuclei at the fold apical portions - X400. d) Specimen from Ganzirri Lake, transverse section of intestinal folds showing apoptotic nuclei along the length of the fold - X100. e) Specimen from Faro Lake showing numerous apoptotic nuclei in the third apical portion - X200. f) Specimen from Faro Lake showing numerous apoptotic nuclei both at the base and along the fold - X100. 
present along the side of the fold (Figure lf) or, rarely, at its base. The characteristic morphology of the late apoptotic process was confirmed by the DAPI staining showing the typical nuclear fragmentation as well as autofluorescent material (Figure 2a-b). It was impossible to identify the apoptotic cell types since they were in the terminal phase of this process. The apoptotic nuclei, like those observed in mammalian intestinal epithelium, were located in the apical epithelial portion. Eosinophilic cells in the lamina propria showed intense aspecific fluorescence.

PCNA immunohistochemistry - In the control fish intestinal epithelium, PCNA ir was present at the basal portion of the intestinal fold. Two differently immunostained nuclei were observed: most of them were intensely stained and were located only at the bottom of the folds sometimes intermingled with a few differentiated cells. In the longitudinally sectioned folds, $7 \pm 1$ strongly immunostained nuclei per half fold were detected; the faintly immunostained nuclei were spread out toward the apical portions along the longitudinal axis of the folds ( $8 \pm 1$ faintly immunostained nuclei per each half fold) (Figure 2c). The faintly immunostained nuclei seem to belong to absorptive and goblet cells. Double staining TUNEL and anti-PCNA put in evidence that the few TUNEL-positive nuclei at the base of the fold seem to be PCNA immunoreactive (Figure $2 d$ ). No immunopositive nuclei were found in the other parts of the folds. In the specimens from Lake Ganzirri and Lake Faro, numerous PCNA immunoreactive nuclei were seen. The strongly immunostained nuclei were located at the bottom and along the side of the basal portion of the folds, spreading to its middle portion longitudinal axis (Figure 2e). In the longitudinally sectioned folds, $20 \pm 3$ strongly immunostained nuclei per half fold were detected; in some folds the immunopositive nuclei are arranged to form a stratified epithelium; the base of the folds loses its architectural organization appearing hyperplastic, as observed in a few specimens from Lake Ganzirri (Figure 2f). The faintly immunostained nuclei are positioned along the long axis of the folds reaching to its mid portion. The strongly immunostained cells do not seem to show any kind of histo-differentiation.

Serotonin immunohistochemistry - In the control fish intestinal wall, serotonin ir was detected in nerve elements only. Scarce serotonin immunoreactive varicose nerve fibres were observed in the lam- ina propria, beneath the intestinal epithelium, while more numerous immunoreactive fibres were found in the myenteric plexus, where immunoreactive neuronal cell bodies were also present (Figure $3 a$ ). No serotonin immunoreactive endocrine cells were present in the proximal intestinal portion.

In specimens from Lake Ganzirri and Lake Faro, numerous serotonin immunoreactive fibres were seen along the lamina propria, underlining the epithelium of the folds, particularly at its basal portion (Figure 3b), and in the myenteric plexus, characterized by strongly immmunostained neuronal cell bodies (Figure $3 \mathrm{c}$ ). Furthermore, it was also possible to put in evidence some serotonin immunoreactive open type endocrine cells in the epithelium at the base of the intestinal folds (Figure $3 d$ ). No differences were observed in fish from the two polluted lakes. The specificity controls gave negative results.

\section{Discussion}

The present study puts into evidence that heavy metal pollution in a natural environment, even if at a non-lethal level, can cause an enhancement in cell proliferation and apoptosis which affects cell renewal and intestinal fold morphology, and alters the serotonin ir distribution pattern in immature specimens of $L$. aurata.

Previous studies have described epithelial cell renewal within the intestine of adult and larval teleosts (Rombout et al., 1984; Stroband and Debets, 1978; Wallace et al., 2005), showing a compartment of proliferating epithelial cells at the base of the intestinal folds. In our control specimens, this compartment is not morphologically differentiated, being more similar to the organization of the mammalian embryonic intestine (Korinek et al., 1998). Proliferating cells, detected as strongly immunostained PCNA nuclei, which are considered to be in the S-phase of the cycle, are intermingled with few differentiated goblet mucous cells. The presence of differentiated cells in the proliferative compartment supports the idea that at least some of the cells can begin differentiation without migrating upward the folds. The hypothesis that a differentiated cell can maintain for a short period the capacity of dividing as suggested by Wallace et al., (2005) in zebrafish and by Rombout et al., (1984) and Stroband and Debets (1978) in other cyprinid fish, does not seem to be supported by our 

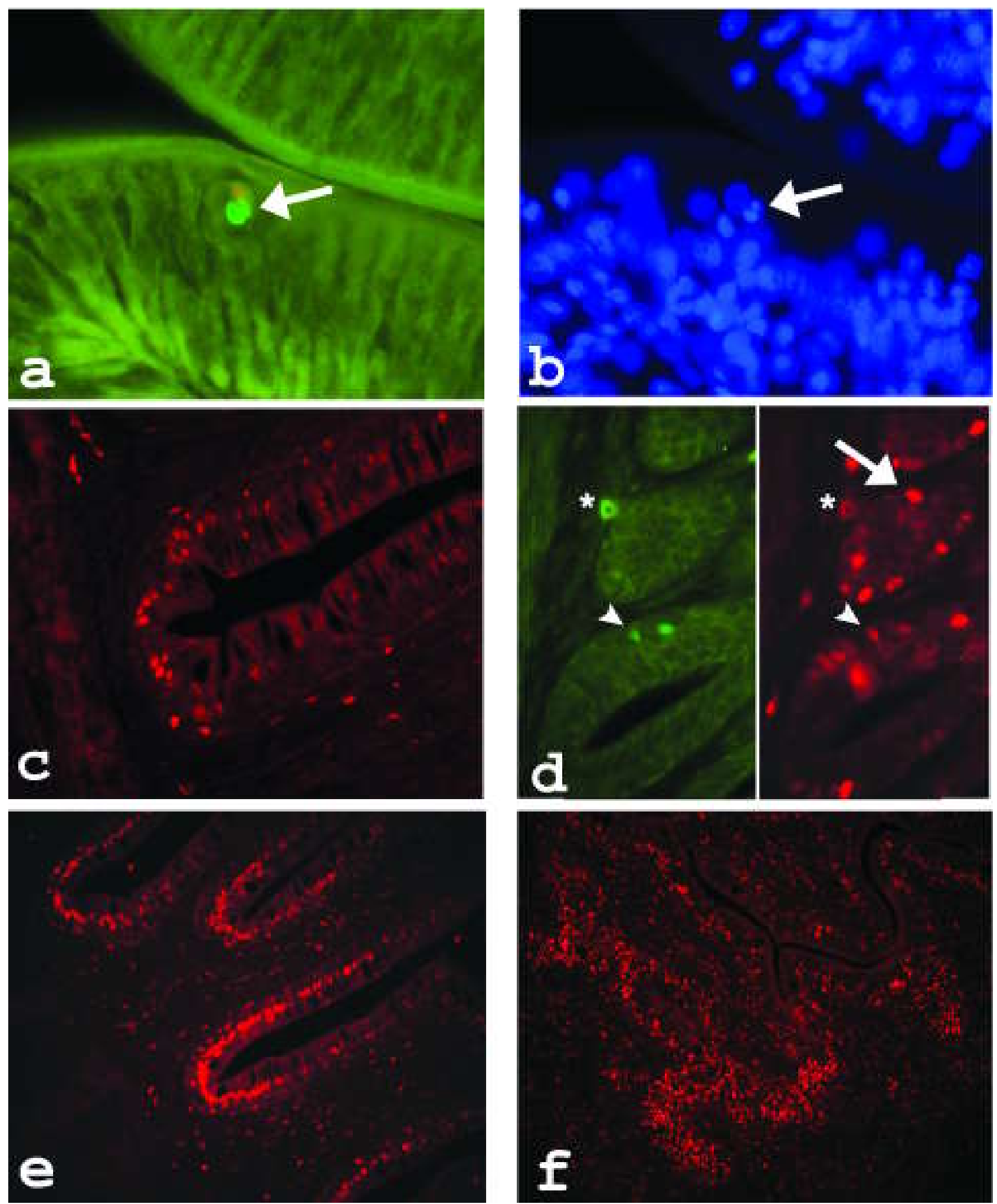

Figure 2. Intestinal folds of $L$. aurata. a) TUNEL method, specimen from Ganzirri Lake, the arrow point to an apoptotic cell with autofluorescent material - X1000. b) DAPI staining, specimen from Ganzirri Lake, The DAPI staining put in evidence the morphology of the apoptotic nucleus showed in fig 2a. Arrow = apoptotic nucleus - X1000. c) PCNA immunohistochemistry, specimen from Verde Lake, immunoreactive cells were located in the basal fold portion - X200. d) TUNEL method (green fluorescence) and PCNA immunohistochemistry (red fluorescence), specimen from Verde Lake, asterisks $=$ red blood cell with aspecific fluorescence, arrowhead $=$ nucleus positive to both methods, arrow = PCNA immunoreactive nucleus negative to TUNEL method - X250. e) PCNA immunohistochemistry, specimen from Ganzirri Lake, numerous immunoreactive cells at the base and along the basal length of the fold - X100. f) PCNA immunohistochemistry, specimen from Faro Lake, iperplastic proliferation - X100. 

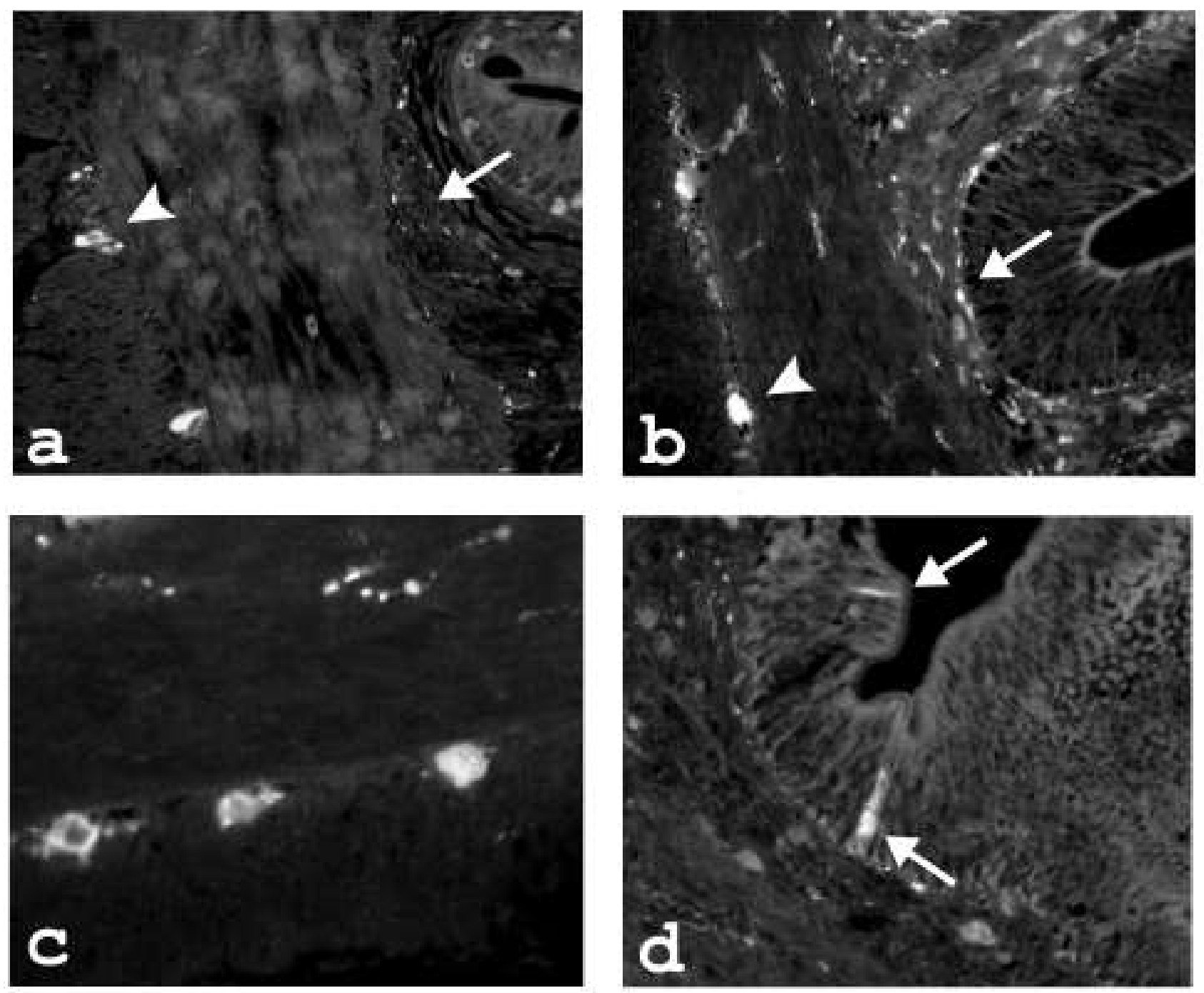

Figure 3. Serotonin immunohistochemistry in the intestine of $L$. aurata. a) Specimen from Verde Lake, in the intestinal wall immunoreactive neuron cell bodies (arrowhead) and nerve fibres (arrow) can be seen - X 200. b) Specimen from Ganzirri Lake, a large number of immunoreactive nerve (arrow) fibres can be observed in the intestinal lamina propria. Arrowhead $=$ neuron cell body $-\mathrm{X200}$. $\mathrm{c}$ ) Specimen from Ganzirri Lake, in the myenteric plexus numerous strongly immunostained neuron cell bodies have been found - X400. d) Specimen from Faro Lake, endocrine cells of the open type in intestinal epithelium (arrows) - X200.

control specimens where differentiated cells (mucous or absorptive), wherever located, never showed strongly immunostained PCNA nuclei. The faint immunostained PCNA nuclei are generally considered to be in the late $\mathrm{G} 1$ or $\mathrm{G} 2$ phase of the cell cycle; in our samples they are probably better considered as belonging to a Gl phase of the next cell cycle, since they were located upward the intestinal folds, and seemed to be already histo-differentiated.

As found in mammals, very few TUNEL-positive cells were detected in the control specimens, and they were located in the proliferative compartment only. Apoptosis should be considered as a normal process by which cell population dynamics are correctly maintained (Waalkes et al., 2000). The presence of a few TUNEL-positive nuclei among proliferative cells, their lacking at the tip of the intestinal folds, and in particular, the finding of both TUNEL-positive and PCNA immunostained nuclei, suggests that, as in mammals, the control of cellular population dynamics in the $L$. aurata intestinal epithelium is located at the base of the folds, regulating proliferating cell number instead of differentiated non proliferating cells.

A more extensive proliferative compartment is 
found in the intestinal mucosa from polluted $L$. aurata specimens, as found in the gut of Atlantic salmon, following toxic levels of dietary heavy metal exposure (Lundebye et al., 1999; Berntssen et al., 2001; 2003), or in some other organs, more commonly used for heavy metal pollution assessment (Piechotta et al., 1997; Kilemade et al., 2002; Feng et al., 2003; Lyons et al., 2004; Rissode Faverney et al., 2004; Mauceri et al. 2005). The increase of proliferative cells in adverse conditions allows us to hypothesize that a larger number of potential stem cells can begin to work, out of necessity, as found in mammals (Potten and Booth, 1997). Our results demonstrated that, not only is there an increase in the number of the $S$ phase cells (strongly PCNA immunostained nuclei) spreading along the intestinal fold till its mid portion, but also of the G2/Gl phase cells (less immunostained PCNA nuclei) suggesting more rapid cell cycles. Furthermore, no differentiated cells are detected in the proliferative compartment that appeared as a hyperplastic zone in fishes from Lake Ganzirri where a higher concentration of iron and cadmium have been demonstrated (Giacobbe et al., 1996; Munaò et al., 2000; Mauceri et al., 2002). The number of TUNEL-positive apoptotic nuclei increases in polluted fishes, but they are located among the differentiated cells and never, or very rarely, can be observed in the proliferative compartment. Apoptotic nuclei are found in the apical third of the intestinal folds, and their frequency of detection suggests a more elevated intestinal damage in samples from Lake Faro; they are more affected by pollution exposure, than those from Lake Ganzirri (Ferrando et al., 2005b); similar results were obtained with alcianophilic mucous cells, indicative of the presence of irritant substances (Sanchez et al., 1997, Ferrando et al., 2005b). These discrepancies in the specimens from the two polluted environments may be related to differences in heavy metal concentrations: in Lake Faro, a higher level of $\mathrm{Hg}$ and $\mathrm{Pb}$ while in Lake Ganzirri, a higher concentration of $\mathrm{Fe}$ and $\mathrm{Cd}$ were detected. In any event, the more numerous proliferative cells versus apoptotic cells might be related to the immature stage of the specimens considered; juveniles are probably more responsive to heavy metal pollution. At present, little information is available about non-lethal heavy metal pollution in natural environments on proliferation and/or apoptotic responses in fish. The impairment of epithelial cell renewal caused by unbalanced cell proliferation and apoptosis could lead to changes of the intestinal fold shape, with reduction of epithelial surface, as previously observed; these morphological modifications are particularly demonstrable in fishes from Lake Ganzirri (Ferrando et al., 2005b).

The damage produced by heavy metal exposure is mainly due to oxidative stress (Berntssen et al., 2003; Elia et al., 2003; Erikson et al., 2004; Galhardi et al., 2004; Krumschnabel \& Nawaz, 2004; Oakes et al., 2004; Risso-de Faverney et al., 2004) and, as a matter of fact, many of the TUNEL-positive cells in our samples show accumulation of autofluorescent substances that could be interpreted as stress pigment in lysosomes (Lawrence et al., 2003).

Serotonin is an evolutionarily conserved neurotransmitter found in both invertebrates and vertebrates, and involved in different physiological and behavioural roles. In the gut, it plays different roles, regulating blood flow, secretion and motility (Olson and Holmgren, 2001).

Serotonin ir is commonly immunodetected in the gut wall of bony fish, being located, as in L. aurata control specimens, in nervous elements only: neuronal cell bodies, myenteric plexus, and nerve fibres throughout the wall. The frequency and the distribution pattern of these serotonin immunoreactive elements varied according to the provenience site considered. In particular, in fish from polluted lakes, the serotonin immunoreactive neuronal cell bodies were detected more frequently, and furthermore, few serotonin immunoreactive endocrine cells appeared at the base of the intestinal folds. The increase of serotonin ir in the samples from Lake Faro and Ganzirri compared to the control, and the appearance of serotonin immunoreactive endocrine cells at the base of intestinal folds may be related to the impairment of intestinal epithelium renewal and might be consequent to heavy metal exposure. Recently, serotonin also has been shown to play a role in cell proliferation and apoptosis through two of its receptor subtypes: the 5-HTIA and the 5HT2A subtypes. In particular, the 5-HT1A receptor promotes differentiation by enhancement and stabilization of the cytoskeleton, while the 5-HT2A receptor is involved in cell proliferation (Azmitia, 2001). The presence of 5-HT2 receptors in crypt cells of mammals is well documented (FioricaHowells et al., 2002), as is its role as a growth and/or survival factor. At present, there are no data 
about the presence of serotonin receptors in fish.

Taken together, these observations suggest that the effects of heavy metal exposure on 5-HT distribution, as documented in different organisms (Salánki \& Hiripi, 1990; Franchini et al., 1999; Antonio et al., 2002; Lafuente et al.2003; Rademacher et al., 2003; Almeida et al., 2003), could be implicated in the adaptive responses of intestinal epithelium of fish, leading to an increase in cell proliferation and apoptosis with morphological alteration of intestinal fold shape.

Care in data interpretation is required, however, since other environmental factors might be involved, and, additional research is necessary to understand the effect of each heavy metal found in various concentrations in the natural environments. Subsequently, statistical analysis should be performed in order to put in evidence the significance of the presented results. Thus, considerable further work and validation are required, but, nevertheless, this study points out that it is possible to detect gut morphophysiological alterations in fish from mild polluted environments.

\section{Acknowledgements}

This research was supported by MIUR, Cofin2001 (Grant No. 2001058987) and Project MEMOBIOMAR (law 248).

\section{References}

Almeida EA, Bainy AC, Medeiros MH, Di Mascio P. Effects of trace metal and exposure to air on serotonin and dopamine levels in tissues of the mussel Perna perna. Mar Poll Bull 2003; 46:1485-90.

Antonio MT, Lopez N, Leret ML. Pb and Cd poisoning during development alters cerebellar and striatal function in rats. Toxicology 2002; 176:59-66.

Au DWT. The application of histo-cytopathological biomarkers in marine pollution monitoring: a review. Mar Poll Bull 2004; 42:81734.

Azmitia EC. Modern views on an ancient chemical: serotonin effects on cell proliferation, maturation and apoptosis. Brain Res Bul 2001; 56:413-24.

Ben-Tuvia A. Mugilidae. In: Whitehead PJP, Bauchot M-L, Hureau JC, Nielsen J, Tortonese E eds. Fishes of the North-eastern Atlantic and the Mediterranean, Vol. III UNESC0, 1986 pp. 1197-204.

Berntssen MHG, Aspholm 00, Hylland K, Wendelaar Bonga SE, Lundebye AK. Tissue metallothionein, apoptosis and cell proliferation responses in Atlantic salmon (Salmo salar L.) parr fed elevated dietary cadmium. Comp Biochem Physiol Part C 2001; 128:299310.

Berntssen MH, Aatland A, Handy RD. Chronic dietary mercury exposure causes oxidative stress, brain lesions, and altered behaviour in Atlantic salmon ( Salmo salar) parr. Aquat Toxicol 2003; 65: 55-72.

Dang Z, Lock RAC, Flink G, Wendelaar Bonga SE. Na+/K+-ATPase immunoraectivity in branchial chloride cells of Oreochoromis mossambicus exposed to copper. J Exp Biol 1999; 203:379-87.

de la Torre FR, Salibian A, Ferrari L. Biomarkers assessment in juvenile Cyprinus carpio exposed to waterborne cadmium. Environ Poll
2000; 109: 277-82.

de Oliveira Ribeiro CA, Belger L, Pelletier É, Rouleau C. Histopatological evidence of inorganic mercury and methyl mercury toxicity in the arctic charr (Salvelinus alpinus). Environ Res 2002; 90:217-25.

Elia AC, Galarini R, Taticchi MI, Dorr AJ, Mantilacci L. Antioxidant responses and bioaccumulation in Ictalurus melas under mercury exposure. Ecotoxicol Environ Saf 2003; 55:162-7.

Erikson KM, Dobson AW, Dorman DC, Aschner M. Manganese exposure and induced oxidative stress in the rat brain. Sci Total Environ 2004; 334-335:409-16.

Feng Q, Boone AN, Vijaiyan M M. Copper impact on heat shock protein 70 expression and apoptosis in rainbow trout hepatocytes. Comp. Biochem. Physiol. Part C: Toxicology and Pharmacology 2003; 135: 345-55.

Ferrando S, Ferrando T, Tagliafierro G, Ferrari R, Mauceri A, Fasulo S. Alterazioni dell'apoptosi e della proliferazione cellulare nelle branchie del teleosteo Liza aurata esposto a metalli pesanti. Lettere GIC 2005a. Submitted.

Ferrando S, Maisano M, Parrino V, Ferrando T, Girosi L, Tagliafierro G. Gut morphology and Metallothionein immunoreactivity in Liza aurata from different heavy metal polluted environment. Italian Journal of Zoology 2005b. Submitted.

Fiorica-Howells E, Hen R, Gingrich J, Li Z, Gershon MD. 5-HT2A receptors: location and functional analysis in the intestines of wildtype and 5-HT2A knockout mice. Am J Physiol Gastrointest Liver Physiol 2002; 282:G877-93.

Fossi MC, Casini S, Marsili L, Neri G, Mori G, Ancora S, Moscatelli A, Ausili A, Notarbartolo-di-Sciara G. Biomarkers for endocrine disruptors in three species of Mediterranean large pelagic fish. Mar Environ Res 2002; 54: 667-71.

Franchini A, Rebecchi B, Bolognani Fantin AM. Gill endocrine cells in the goldfish Carassius carassius var. auratus and their impairment following experimental lead intoxication. Histochem J 1999; 31: 559-64.

Galhardi CM, Diniz YS, Faine LA, Rodrigues HG, Burneiko RC, Ribas BO, Novelli EL. Toxicity of copper intake: lipid profile, oxidative stress and susceptibility to renal dysfunction. Food Chem Toxicol 2004; 42: 2053-60.

Giacobbe MG, Oliva FD, Maimone G. Environmental factors and seasonal occurrence of the Dinoflagellate Alexandrium minutum, a PSP potential producer, in a Mediterranean lagoon. Estuarine, Coastal and Shelf Science 1996; 42: 539-49.

Kilemade M, Lyons-Alcantara M, Rose T, Fitzgerald R, Mothersill C. Rainbow trout primary epidermal cell proliferation as an indicator of aquatic toxicity: an in vitro/in vivo exposure comparison. Aquat Toxic 2002; 60: 43-59.

Korinek V, Barker N, Moerer P, van Donselaar E, Huls G, Peters PJ, Clevers $\mathrm{H}$. Depletion of epithelial stem-cell compartments in the small intestine of mice lacking Tcf-4. Nature Genet 1998; 19: 37983.

Krumschnabel G, Nawaz M 2004. Acute toxicity of hexavalent chromium in isolated teleost hepatocytes. Aquat Toxicol 2004; 70: 159-67.

Lafuente A, Gonzales-Carracedo A, Romero A, Esquifino AI. Effect of cadmium on 24-h variations in hypothalamic dopamine and serotonin metabolism in adult male rats. Exp Brain Res 2003; 149: 200-6.

Lawrence AJ, Arukwe A, Moore M, Sayer M, Thain J. Molecular/Cellular Processes and the Physiological Response to Pollution. In: Lawrence AJ, Hemingway KL eds. Effects of Pollution on Fish. Molecular Effects and Population Responses, Blackwell Publishing, 2003, pp. 83-133.

Lundebye A-K, Berntssen MHG, Wendelaar Bonga SE, Maage A. Biochemical and Physiological responses in atlantic salmon (Salmo salar) following dietary exposure to copper and cadmium. Mar Poll Bull 1999; 39: 137-44.

Lyons BP, Bignell J, Stentiford GD, Feist SW. The viviparous blenny (Zoarces viviparus) as a bioindicator of contaminant exposure: application of biomarkers of apoptosis and DNA damage. Mar Environ Res 2004; 58: 757-61.

Mauceri A, Tigano C, Ferrito V, Barbaro B, Calderaio M, Ainis L, Fasulo S. Effect of natural confinement on the gill cell types and bony elements of Lebias fasciata (Teleostei, Cyprinodontidae): a 
morphological and immunoistochemical analysis. Ital J Zool 2002; 69: 195-203.

Mauceri A, Fossi MC, Leonzio C, Ancora S, Minniti F, Maisano M, Lo Cascio P, Ferrando $S$, Fasulo $S$. Stress factors in the gills of Liza aurata (Mugilidae, Teleosts) living in polluted environments. Ital J Zool 2005; in press.

Munaò F, Di Pietro A, Scoglio ME, Piperno I. Elementi in traccia nel complesso lagunare Ganzirri-Faro. Rischio sanitario. Igiene Moderna 2000; 114: 243-60.

Mzimela HM, Wepener $V$, Cyrus DP. Seasonal variation of selected metals in sediments, water and tissues of the groovy mullet, Liza dumerelii (Mugilidae) from the Mhlathuze Estuary, South Africa. Mar Pol Bull 2003; 46: 659-76.

Oakes KD, McMlaster ME, Van Der Kraak GJ. Oxidative stress responses in longnose sucker (Catostomus catostomus) exposed to pulp and paper mill and municipal sewage effluents. Aquat Toxicol 2004; 67: 255-71.

Olsson C, Holmgren S. The control of gut motility. Comp Biochem Physiol Part A 2001; 128: 479-501.

Ortego LS, Hawkins WE, Walker WW, Krol RM, Benson WH. Immunoistochemical detection of proliferating cell nuclear antigen (PCNA) in tissues of aquatic animals utilized in toxicity bioassays. Mar Environ Res 1995; 39: 271-3.

Pedersen SN, Lundebye A-K, Depledge MH. Field application of metallothionein and stress protein biomarkers in the shore crab (Carcinus maenas) exposed to trace metals. Aquatic Toxicol 1997; 37: 183-200.

Piechotta G, Lacom M, Lang T, Kammann U, Simat T, Jenke H-S, et al. Apoptosis in dab ( Limanda limanda) as possible new biomarkerfor anthropogenic stress. Ecotox Environ Saf 1997; 42: 50-6.

Potten CS, Booth $\mathrm{C}$. The role of radiation-induced and spontaneus apoptosis in the homeostasis of the gastrointestinal epithelium: a brief review. Comp Biochem Physiol 1997; 118B: 473-478.

Radecki SV, Ku PK, Bennink MR, Yokoyama MT, Miller ER. Effect of dietary copper on intestinal mucosa enzyme activity, morphology and turnover rates in wealings pigs. J Anim Sci 1992; 70: 1424-31.

Rademacher DJ, Steinpreis RE, Weber DN. Effects of dietary lead and/or dimercaptosuccinic acid exposure on regional serotonin and serotonin metabolite content in rainbow trout (Oncorhynchus mykiss). Neurosci Lett 2003; 339: 156-60.

Rasband, W. S., 2005. ImageJ. U. S. National Institutes of Health. Bethesda, Maryland, USA. http://rsb.info.nih.gov/ij/

Regione Sicilia, Assessorato Territorio e Ambiente. "Relazione sullo stato dell'ambiente in Sicilia, 2002".

Risso-de Faverney C, Orsini N, de Sousa G, Rahmani R. Cadmiuminduced apoptosis through the mitochondrial pathway in rainbow trout hepatocytes: involvement of oxidative stress. Aquat Tox 2004; 69: 247-58.

Rombout JH, Stroband HW, Taverne-Thiele JJ. Proliferation and differentiation of intestinal epithelial cells during development of Barbus conchonius (Teleostei, Cyprinidae). Cell Tissue Res 1984; 236: 207-16.

Salánki J, Hiripi L. Effect of heavy metals on the serotonin and dopamine systems in the central nervous system of the freshwater mussel (Anodonta cygnea L.). Comp Biochem Physiol Part C: Comparative Pharmacology 1990; 95: 301-5.

Sanchez J.G., Speare D.J., Johnson G.J., 1997 - Morphometric and histochemical assessment of the branchial tissue response of rainbow trout, Oncorhynchus mykiss (Walbaum), associated with chloramine-T treatment. J.Fish Diseases, 20: 375-81.

Stentiford GD, Longshaw M, Lyons BP, Jones G, Green M, Feist, SW. Histopathological biomarkers in estuarine fish species for the assessment of biological effects of contaminants. Mar Environ Res 2003; 55: 137-59.

Stroband HW, Debets FM. The ultrastructure and renewal of the intestinal epithelium of the juvenile grasscarp, Ctenopharyngodon idella (Val.). Cell Tissue Res 1978; 187 (2): 181-200.

van der Oost R, Beyer J, Vermeulen NPE. Fish bioaccumulation and biomarkers in environmental risk assessment: a review. Environ Tox Pharm 2003; 13: 57-149.

Wallace KN, Akhter S, Smith EM, Lorent K, Pack M. Intestinal growth and differentiation in zebrafish. Mechanisms of Development 2005; 122: 157-73.

Waalkes MP, Fox DA, States C, Patierno SR, McCabe MJ. Metals and disorders of cell accumulation: Modulation of apoptosis and cell proliferation. Toxic Sci 2000; 56: 255-61.

Wendelaar Bonga SE, Lock RAC. Toxicans and osmoregulation in fish. Neth J Zool 1992; 42: 478-93. 